\title{
Intervertebral disc decompression following endplate damage:
}

\section{implications for disc degeneration depend on spinal level and age}

Patricia Dolan PhD, Jin Luo PhD*, Phillip Pollintine PhD, Priyan R. Landham FRCS (Orth), Manos Stefanakis $\mathrm{PhD}^{+}$, Michael A. Adams PhD

Centre for Comparative and Clinical Anatomy, University of Bristol, Bristol, UK

* Dept. of Life Sciences, University of Roehampton, U.K.

${ }^{+}$Dept. of Health Sciences, European University of Cyprus

\section{Corresponding author:}

Dr Patricia Dolan,

Reader in Biomechanics,

Centre for Comparative and ClinicalAnatomy,

University of Bristol,

Southwell Street,

Bristol BS2 8EJ, U.K.

Trish.Dolan@bris.ac.uk

Tel: +44 (0) 1179288363

Fax: +44 (0) 1179254794

KEY WORDS: intervertebral disc degeneration; phenotype; endplate fracture; spinal level; intradiscal pressure.

Acknowledgements This work was funded in the U.K. by Action Medical Research, the Royal College of Surgeons of England, the Gloucestershire Arthritis Trust, BackCare, and the Greek Institute of Scholarships (I.K.Y).

Ethics: Research approved by the NRes ethics committee, Frenchay Hospital, Bristol, U.K. 


\section{Abstract}

Study Design Mechanical and morphological studies on cadaveric spines.

Summary of Background Data Disc degeneration can be initiated by damage to a vertebral body endplate, but it is unclear why endplate lesions, and patterns of disc degeneration, vary so much with spinal level and age.

Objective Explain how spinal level and age influence disc degeneration arising from endplate fracture.

Methods 174 cadaveric 'motion segments', from T7-8 to L5-S1 and aged 19-96 yrs, were subjected to controlled compressive overload to damage a vertebral body. 'Stress profilometry' was performed before and after damage in order to quantify changes in intradiscal pressure (IDP), and compressive stresses in the annulus. 86 of the undamaged vertebral bodies were then sectioned in the mid-sagittal plane, and the thickness of the central bony endplate was measured from microradiographs. Regression analysis was used to compare the relative influences of spinal level, age, disc degeneration and gender on results obtained.

Results Compressive overload caused endplate fracture at an average force of $3.4 \mathrm{kN}$, and reduced vertebral body height by an average $1.88 \mathrm{~mm}$. Pressure loss in the adjacent nucleus pulposus decreased from $93 \%$ at $\mathrm{T} 8-9$ to $38 \%$ at $\mathrm{L} 4-5\left(\mathrm{R}^{2}=22 \%, \mathrm{P}<0.001\right)$, and increased with age $\left(\mathrm{R}^{2}=19 \%, \mathrm{P}<0.001\right)$ especially in male specimens. Stress concentrations in the posterior annulus increased following endplate fracture, with the effect being greatest at upper spinal levels $\left(\mathrm{R}^{2}=7 \%, \mathrm{P}<0.001\right)$. Endplate thickness increased by approximately $50 \%$ between $\mathrm{T} 11$ and $\mathrm{L} 5\left(\mathrm{R}^{2}=21 \%, \mathrm{P}<0.001\right)$. 
Conclusion Endplate fracture creates abnormal stress distributions in the adjacent intervertebral disc, increasing the risk of internal disruption and degeneration. Effects are greatly reduced in the lower lumbar spine, and in young specimens, primarily because of differences in nucleus volume, and materials properties, respectively. Disc degeneration between L4 and S1 may often be unrelated to endplate fracture. 


\section{Key Points}

1. Disc degeneration can be initiated by damage to a vertebral endplate, but why should disc and endplate lesions vary so greatly with spinal level and age?

2. Experiments on 174 cadaveric motion segments (aged 19-96 yrs, from T7-8 to L5-S1) showed that compressive overload always damaged a vertebral body endplate and decompressed the adjacent intervertebral disc.

3. The severity of disc decompression depended primarily on spinal level, decreasing linearly from $93 \%$ at $\mathrm{T} 8-9$ to $38 \%$ at $\mathrm{L} 4-5\left(\mathrm{R}^{2}=22 \%, \mathrm{P}<0.001\right)$, and was lower in young male specimens. Variations appeared to depend on systematic differences in nucleus volume and endplate thickness.

4. Results suggest that disc degeneration at L4-5 and L5-S1 may often be unrelated to endplate fracture. 


\section{Précis}

Experiments on cadaveric spines showed that endplate fracture always decompresses the adjacent nucleus pulposus, and concentrates compressive stress in the posterior annulus fibrosus. Effects are much reduced in the lower lumbar spine, and in young specimens, as a result of increased nucleus volume and thicker endplates. Disc degeneration between L4 and S1 may often be unrelated to endplate fracture. 


\section{Introduction}

Recent population studies show a strong dose-response relationship between intervertebral disc degeneration and chronic low back pain. ${ }^{1-3}$ However, the relationship is weak if degeneration is defined in terms of age-related water loss, ${ }^{4-5}$ and strong if 'degeneration' involves structural features such as radial fissures, ${ }^{6-7}$ posterior herniation, ${ }^{8}$ endplate defects, ${ }^{9}$ and reinnervation ${ }^{10-11}$.

This disagreement highlights a growing problem: 'disc degeneration' encompasses a range of features, each with its own risk factors, and opportunities for intervention. Only when the disc finally collapses can the process be likened to a single disease, and by then it may be too late for effective intervention apart from surgery. Clearly there is a need to distinguish between separate disc degeneration 'phenotypes' earlier in the degeneration process, so that distinct pathological processes can be treated or prevented more effectively.

With this in mind, we recently contrasted 'endplate-driven' and 'annulus-driven' disc degeneration. ${ }^{12}$ The former is characterised by an endplate fracture, inwards collapse of the annulus, high heritability, and a distribution predominantly in the upper lumbar and thoracic spine. In contrast, 'annulus-driven' degeneration is characterised by a radial fissure and/or disc prolapse, low heritability, and a distribution predominantly in the lower lumbar spine (L4-S1). The distinction is simplistic (endplates can be damaged at L4 and L5, and upper lumbar discs can herniate) but it is consistent with a diverse range of evidence, and it suggests why spinal level should exert such a strong influence on spinal pathology. ${ }^{13-15}$ One experimental finding in particular supports this 'two-phenotypes' concept: severe mechanical loading is more likely to create radial fissures and herniation in lower lumbar discs than in upper lumbar discs. ${ }^{16-17}$ However, there is no corresponding evidence that upper lumbar and 
thoracic discs are more vulnerable to endplate fracture, and its sequellae, than are lower lumbar discs.

We hypothesise that endplate damage arising from excessive spinal compression causes major decompression of thoracic and upper lumbar discs, but only minor decompression of lower lumbar discs. Nucleus decompression following endplate fracture has been shown to cause progressive internal disruption in cadaveric discs, ${ }^{18}$ leading to realistic disc degeneration in an animal model. ${ }^{19}$

\section{Materials and Methods}

Cadaveric material Thoracolumbar spines from donated cadavers were stored at $-20^{0} \mathrm{C}$ before being dissected into 'motion segments' comprising one or two discs and their adjacent vertebrae. $^{20-23}$ Details of the 174 tested discs are summarised in Table 1.

Stress profilometry Each motion segment was mounted in plaster (Figure 1) and loaded on a materials testing machine. ${ }^{20}$ During testing, specimens were wrapped in plastic film to

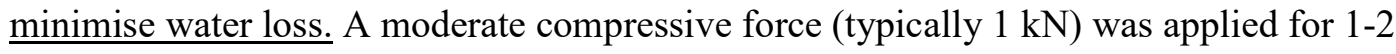
hours in order to dehydrate the disc by an amount similar to that seen in-vivo during a day's activity, ${ }^{24}$ hence ensuring that disc hydration was well within the normal physiological $\underline{\text { range. After the creep loading period, a pressure transducer (side-mounted in a } 1.3 \mathrm{~mm}-}$ diameter needle) was inserted into the disc and pulled across its mid-sagittal diameter to measure the distribution of compressive "stress". 25 These "stress profiles" were usually obtained at a compressive load of $1 \mathrm{kN}$ with the specimen positioned either in the neutral position $\left(0^{\circ}\right)$ or in $2^{\circ}$ of extension, to simulate typical erect postures in life. Vertical and horizontal stress was measured in successive tests by rotating the transducer needle about its axis. Intradiscal pressure (IDP) in the nucleus, and peak compressive stresses in the annulus (over and above nucleus pressure), were then measured from the 'profiles'. ${ }^{22}$ For some 
specimens, the compressive force during creep loading and stress profilometry was changed to $0.5 \mathrm{kN}$ or $2 \mathrm{kN}$, depending on specimen size and age, but all intradiscal measurements were subsequently scaled to an applied load of $1 \mathrm{kN}$ for comparison. Stress profilometry has been validated ${ }^{26-28}$ and linearity between measured 'stress' and applied load has been demonstrated. $^{29}$

Compressive overload With the specimen positioned in moderate flexion (to simulate the flat back of a weight-lifter ${ }^{30}$ ) the compressive force was increased by moving the ram of the testing machine upwards at $3 \mathrm{~mm} / \mathrm{s}$. Loading was removed at a pre-determined maximum displacement which depended on specimen size and age, and the force-deformation graph was inspected for evidence that the yield point had been exceeded. ${ }^{20}$ If not, the specimen was loaded to a higher maximum displacement. Eventually, the first sign of injury was revealed by a reduction in gradient of the force-deformation graph. Endplate damage was confirmed by radiographs, ${ }^{31}$ and quantified by repeating the loading cycle up to the failure load, and noting the extent to which it was shifted along the $\mathrm{X}$ (displacement) axis. ${ }^{20}$ The X-shift (in $\mathrm{mm})$, recorded at a load of $1 \mathrm{kN}$, indicated motion segment height loss.

Optical measurements of vertebral body deformation To help interpret the Dartec-based measurements of motion segment height loss, a single-camera MacReflex system was used to measure deformation of the damaged vertebral body independently of deformation of the disc, the non-damaged vertebral body, and the apparatus ${ }^{23}$. This technique can be subject to large errors if vertebral damage disturbs the reflective markers, which is more likely to occur in smaller thoracic vertebrae. Therefore, these measurements were obtained in 15 specimens from T11-12 to L4-5. In these specimens, three pairs of reflective markers were attached to the lateral cortex of each vertebral body tested (Figure 1) so that anterior, middle and posterior vertebral body heights could be measured, ${ }^{23}$ to an accuracy of $10 \mu \mathrm{m} .{ }^{32}$ Height 
measurements were compared before and after compressive damage in order to calculate cortical height loss in $\mathrm{mm}^{23}$

Specimen morphology After testing, each specimen was dissected and photographed to confirm the site(s) of fracture. The macroscopic appearance of each disc, and its height on pre-fracture radiographs, were used to grade disc degeneration from 1 to 4 , using the first four points on a scale described previously. ${ }^{33}$

Endplate thickness 86 of the non-damaged vertebral bodies, sampled so that all age groups and spinal levels were represented, were sectioned in the sagittal plane. Subsequent microradiographs of $2 \mathrm{~mm}$-thick slices were analysed to measure the thickness of the cranial and caudal bony endplates at 10 equidistant sites along the mid-sagittal section. Because fracture primarily affects the central endplate, thickness was averaged across sites 4, 5,6 and $\underline{7, \text { which lie adjacent to the inner annulus and nucleus. }} .{ }^{34}$

Statistical analyses Linear regression was used to determine which variable factors had the greatest influence on disc decompression and vertebral damage (height loss).

\section{Results}

Initial measurements on 174 undamaged specimens showed that IDP averaged $0.88 \mathrm{MPa}$ (for a reference compressive force of $1 \mathrm{kN}$ ) and decreased from $0.98 \mathrm{MPa}$ in 'grade 1' discs to 0.47 MPa in severely degenerated 'grade 4' discs (Table 2, column 4). IDP also decreased with spinal level, from 1.56 MPa at T7-8, to $0.73 \mathrm{MPa}$ at L5-S1.

Compressive overload always damaged a bony endplate, although some specimens showed additional vertebral damage to the anterior cortex and/or trabeculae. The compressive force at the initiation of damage averaged $3.4 \mathrm{kN}$ (range 0.9 - $11.6 \mathrm{kN})$. Motion segment height loss averaged $1.88 \mathrm{~mm}$ and was greatest in old female specimens and in those with degenerated discs (Table 2, column 5). Height loss averaged $2.27 \mathrm{~mm}$ at T7-8, but was less 
in the lumbar spine, falling to $0.46 \mathrm{~mm}$ at L5-S1. Optical measurements showed that height loss averaged $17 \%, 11 \%$ and $4 \%$ in the anterior, middle and posterior regions of the lateral vertebral body cortex of the damaged vertebra, indicating slight anterior wedging.

Vertebral damage reduced IDP in the adjacent disc, by an average $0.54 \mathrm{MPa}$, which is equivalent to a $62 \%$ loss. In contrast, maximum compressive stress in the posterior annulus (over and above nucleus pressure) increased by $0.74 \mathrm{MPa}$. Nucleus decompression varied greatly with spinal level, from 1.28 MPa at T7-8 to 0.24 MPa at L4-5 (Table 2, column 7). The influence of spinal level did not depend much on whether the discs were degenerated (grades 3 and 4) or not (grades 1 and 2), as shown in Figure 2, or on whether decompression was measured in absolute (MPa) or relative (\%) terms (Table 2). Nucleus decompression also increased linearly with age in male specimens, whereas nearly all female specimens over the age of 40 yrs were substantially decompressed (Figure 3). Similar age-related trends were present if decompression was quantified in absolute or relative terms.

Univariate regression analysis (Table 3) showed that the greatest influence on the extent of vertebral damage was spinal level, which explained $20 \%$ of variance in all specimens, and $34 \%$ in specimens with non-degenerated discs (Table 3, row 3). Vertebral damage also increased with age (Table 3, row 1) and with female gender (Table 2, column 5). Damage was in turn a major influence in disc decompression, explaining $20 \%$ of the fall in IDP in all specimens, and 47\% in specimens with non-degenerated discs (Table 3, row 14). Age explained $19 \%$ of the variance in \% disc decompression. However, absolute changes in intradiscal stresses (MPa) following vertebral damage depended less on age than on initial IDP (Table 3, rows $13 \& 18$ ) which itself decreased with age and disc degeneration (Table 2, column 4). Peak compressive stress in the posterior annulus (relative to IDP) increased in proportion to the fall in IDP (Table 3, row 20), and increased most when initial IDP was high 
(Table 3, row 18). Changes in peak compressive stresses in the anterior annulus (not shown) were variable, and unrelated to other variables in Table 3.

Multiple linear regression revealed the greatest influences on disc decompression. If the three independent variables (age, gender and spinal level) were forced into the analysis, they explained $38 \%$ of the variance in 'Fall in IDP (MPa)'. However, adding 'Initial IDP (MPa)', 'Damage (mm)', and 'disc degeneration (graded 1-4)' to the model enabled it to explain $71 \%$ of the variance in disc decompression (Table 4). Additional multivariate analyses revealed that 'Initial IDP (MPa)' itself depended on spinal level, age, and gender (in decreasing order of importance) but the influence of disc degeneration was marginal.

Thickness of the bony endplate is compared at various spinal levels (Figure 4). Values in Figure 4 represent the average thickness (of both endplates of each vertebral body) in the central region, adjacent to the nucleus and inner annulus, because this is where fracture generally occurs ${ }^{34}$. Thickness increased by approximately $50 \%$ between $\mathrm{T} 11$ and L5 $\left(\mathrm{R}^{2}=\right.$ $21 \%, \mathrm{P}<0.001)$. Endplate thickness was measured on 86 undamaged vertebrae, and so was not compared directly with failure characteristics such as specimen strength.

\section{Discussion}

Summary of findings Compressive overload always damaged a vertebral body endplate and decompressed the adjacent nucleus pulposus. Decompression was greatest in old specimens, in those with degenerated discs, and in the upper lumbar and thoracic spine. Thickness of the bony endplates increased between T11 and L5.

Strengths and weaknesses of the investigation. Many specimens were tested so that influences such as age and spinal level might be distinguished. All techniques have been validated, as discussed above. Vertebral endplate fractures were obtained by compressing them via the adjacent disc, and their radiographic appearance (which included some anterior 
wedging) was similar to fractures seen clinically. ${ }^{31}$ The use of cadaveric tissues introduces little artefact, ${ }^{35}$ and measurements of intradiscal pressure (IDP) are similar to those made invivo, ${ }^{36-38}$ showing similar variation with degeneration. ${ }^{39}$

Working with dead tissues ensures that long-term consequences of endplate damage can only be estimated. Also, specimens were not distributed evenly between spinal levels and age groups, with relatively few specimens from L5-S1, and few young specimens from thoracic levels (Table 1). Measurements of vertebral damage would have been influenced by the loading protocol, but their dependence on age and gender (Table 3) accurately reflects the fact that, in life, vertebral collapse is greatest in old female vertebrae.

Relationship to previous studies. Compressive overload has been shown primarily to damage the vertebral endplate ${ }^{40-42}$ and its supporting trabeculae. ${ }^{43}$ Spinal flexion and endplate fracture both transfer load-bearing to the anterior vertebral cortex, ${ }^{23,44}$ explaining why anterior cortical damage was substantial in the present experiments. Endplate damage decompresses the adjacent disc, ${ }^{45-46}$ leading to internal collapse of the inner annulus, ${ }^{18}$ and increased radial bulging of the outer annulus, ${ }^{43}$ both of which are common features of disc degeneration in-vivo. ${ }^{47-48}$ The novelty of the present experiment is to show how disc decompression varies with factors such as spinal level and age.

Explanation of findings Damaged endplates bulge more into the vertebral body ${ }^{43}$ allowing more space for the disc nucleus. This reduces nucleus pressure, which is sensitive to small $\%$ changes in volume. ${ }^{49}$ Greater damage causes greater nucleus decompression, and correspondingly greater peak stresses in the annulus, as load-bearing is shifted from nucleus to annulus, and to the neural arch. ${ }^{22}$ The following discussion suggests why this mechanism depends primarily on spinal level, age/degeneration and gender, and secondarily on factors such as 'Damage (mm)' which themselves depend on the primary variables. 
The influence of spinal level has several likely causes, the most important of which is probably the greater height of lower lumbar discs. Disc height increases substantially in the lower thoracic spine ${ }^{50}$ and by $100-150 \%$ between T7-8 and L5-S1, ${ }^{51}$ so nucleus volume will increase by at least this amount. Decompression following endplate damage is proportional to nucleus volume, and so will be reduced at lower lumbar levels. The greater height of lower lumbar discs leads to greater vertical deformations and radial bulging under load, ${ }^{51}$ enhancing the disc's ability to equalise compressive stress and reducing nucleus decompression. Increasing disc cross-sectional area at lower spinal levels ${ }^{40}$ may also exert an influence, because it will cause the $1 \mathrm{kN}$ load to give rise to a lower 'initial IDP', which in turn may cause a smaller pressure drop following endplate damage. However, endplate area increases by only $17 \%$ between $\mathrm{L} 1$ and $\mathrm{L} 5^{52}$, whereas disc decompression across these same levels decreased by $59 \%$ (calculated from Table 2 column 7) so the influence of endplate area is not paramount. Finally, thicker vertebral endplates in the lower lumbar spine (Figure 4) may minimise endplate deformations and disc pressure changes following endplate damage. The influence of age (Figure 3) is also complex. Nucleus pressure decreases with age and disc degeneration ${ }^{39},{ }^{25}$ and a lower 'Initial IDP' will naturally cause a greater $\%$ fall in IDP following endplate damage for the same absolute pressure drop. Age also makes vertebrae more brittle, so that they lose more height when damaged and cause greater disc decompression. Hence, the marked gender differences shown in Figure 3 could be explained in terms of increasing bone fragility in women after the menopause. Annulus tissue also stiffens with age as a result of non-enzymatic glycation, ${ }^{53}$ so an old stiff annulus may be better able to stress-shield the nucleus than the soft hydrated annulus of a young nondegenerated disc, which can deform and equalise stress.

The influence of age and spinal level on nucleus decompression can be compared as follows: age probably exerts its influence by increasing annulus stiffness and bone fragility, whereas 
spinal level probably exerts its influence via annulus height and nucleus volume. Although both influences are large, it is evident from Table 2 that only spinal level has a major influence on absolute pressure loss in the nucleus (in MPa) and on absolute stress increases in the posterior annulus. Absolute changes in intradiscal stress may be more important than $\%$ changes when it comes to driving disc disruption and degeneration.

The influence of gender can be explained in terms of increased bone fragility in women, and also on the reduced size and endplate area in female spines, which would increase initial disc pressure and lead to greater damage and subsequent pressure changes in the disc (Table 2).

Clinical implications. Disc decompression and 'internal disc disruption' is common in the thoracolumbar spine. ${ }^{47}$ From a biological point of view, low pressure in the nucleus and increased stresses in the annulus will inhibit disc cell metabolism ${ }^{54}$ and increase synthesis of matrix-degrading enzymes. ${ }^{55-56}$ In this way, endplate failure would initiate biological degenerative changes in the disc. This mechanism of disc degeneration has been demonstrated in animals, ${ }^{19,57}$ explained by organ culture ${ }^{56}$ and mathematical models, ${ }^{58}$ and confirmed in humans. ${ }^{59}$

Decompression, and loss of disc height, following endplate fracture are associated with an increase in neutral zone and hence with instability. ${ }^{20}$ Greater decompression of thoracic and upper lumbar discs therefore explains why degenerative disc narrowing and osteophytes, which are typical in this region of the spine, ${ }^{50,60}$ are so closely associated with large centrally-located Schmorl's nodes. ${ }^{14}$ Some nodes may be congenital, ${ }^{41}$ but others are related to loading ${ }^{15}$ and represent calcification around a vertical herniation of nucleus pulposus. Thoracic disc degeneration tends not to lead to severe radial bulging, ${ }^{50}$ possibly because the discs are inherently narrow and better stress-shielded by the neural arch, and thoracic disc degeneration is only 'modestly' associated with back pain. ${ }^{61}$ 
The situation is very different between L4 and S1, where Schmorl's nodes are relatively uncommon $^{15,62}$ and less associated with disc degeneration. ${ }^{14}$ This can be explained by the present results: thicker endplates between L4 and S1 reduce the risk and size of vertical disc herniations, and the hence the tendency for the disc to degenerate via this mechanism. Most lower lumbar endplate lesions are characterised as 'erosions/calcification' rather than 'Schmorl's nodes/fractures', ${ }^{15}$ and are associated with inflammation in the vertebral body. ${ }^{63-}$ 64 They may reflect posterior disc herniations in which displaced annulus strips cartilage from the bony endplate, ${ }^{65-66}$ allowing inflammatory reactions to occur. Many disc herniations involve disruption of cartilage and bone on the postero-lateral margins of the vertebral body. $^{67}$

These interpretations support the concept of two disc degeneration phenotypes ${ }^{12}$ : 'endplatedriven' degeneration in the upper lumbar and thoracic spine which is initiated by endplate damage as simulated in the present experiment; and 'annulus driven' degeneration at L4-5 and L5-S1 which is initiated by nucleus tissue herniating through the annulus. Both of the initiating lesions decompress the nucleus, making it less likely that the other type of lesion could occur in the same disc.

Unanswered questions and future research. Longitudinal clinical studies are required to prove that different mechanisms lead to disc degeneration at L4-S1 compared to higher spinal levels.

Conclusions Even minor damage to a vertebral body endplate can decompresses the adjacent disc, allowing the annulus to collapse inwards. The effect is small in young and lower lumbar discs, possibly because they have a larger nucleus volume, and thicker endplates. In life, degeneration of L4-S1 discs may often be unrelated to endplate fracture. 


\section{References}

1. Cheung KM, Karppinen J, Chan D, et al. Prevalence and pattern of lumbar magnetic resonance imaging changes in a population study of one thousand forty-three individuals. Spine 2009;34:934-40.

2. de Schepper EI, Damen J, van Meurs JB, et al. The association between lumbar disc degeneration and low back pain: the influence of age, gender, and individual radiographic features. Spine 2010;35:531-6.

3. Bendix T, Kjaer P, Korsholm L. Burned-out discs stop hurting: fact or fiction? Spine 2008;33:E962-7.

4. Videman T, Battie MC, Gibbons LE, Maravilla K, Manninen H, Kaprio J. Associations between back pain history and lumbar MRI findings. Spine 2003;28:582-8. 5. Boos N, Rieder R, Schade V, Spratt KF, Semmer N, Aebi M. 1995 Volvo Award in clinical sciences. The diagnostic accuracy of magnetic resonance imaging, work perception, and psychosocial factors in identifying symptomatic disc herniations. Spine 1995;20:261325.

6. Videman T, Nurminen M. The occurrence of anular tears and their relation to lifetime back pain history: a cadaveric study using barium sulfate discography. Spine 2004;29:266876.

7. Peng B, Hou S, Wu W, Zhang C, Yang Y. The pathogenesis and clinical significance of a high-intensity zone (HIZ) of lumbar intervertebral disc on MR imaging in the patient with discogenic low back pain. Eur Spine J 2006;15:583-7.

8. Jensen MC, Brant-Zawadzki MN, Obuchowski N, Modic MT, Malkasian D, Ross JS. Magnetic resonance imaging of the lumbar spine in people without back pain. N Engl J Med 1994;331:69-73. 
9. Hamanishi C, Kawabata T, Yosii T, Tanaka S. Schmorl's nodes on magnetic resonance imaging. Their incidence and clinical relevance. Spine 1994;19:450-3.

10. Freemont AJ, Peacock TE, Goupille P, Hoyland JA, O'Brien J, Jayson MI. Nerve ingrowth into diseased intervertebral disc in chronic back pain. Lancet 1997;350:178-81. 11. Coppes MH, Marani E, Thomeer RT, Groen GJ. Innervation of "painful" lumbar discs. Spine 1997;22:2342-9; discussion 9-50.

12. Adams MA, Dolan P. Intervertebral disc degeneration: evidence for two distinct phenotypes. Journal of Anatomy 2012;221:497-506.

13. Battie MC, Videman T, Levalahti E, Gill K, Kaprio J. Genetic and environmental effects on disc degeneration by phenotype and spinal level: a multivariate twin study. Spine 2008;33:2801-8.

14. Mok FP, Samartzis D, Karppinen J, Luk KD, Fong DY, Cheung KM. ISSLS prize winner: Prevalence, determinants, and association of Schmorl nodes of the lumbar spine with disc degeneration: a population-based study of 2449 individuals. Spine (Phila Pa 1976) 2010;35:1944-52.

15. Wang Y, Videman T, Battie MC. ISSLS Prize Winner: Lumbar Vertebral Endplate Lesions: Associations With Disc Degeneration and Back Pain History. Spine (Phila Pa 1976) 2012;37:1490-6.

16. Adams MA, Hutton WC. Prolapsed intervertebral disc. A hyperflexion injury 1981 Volvo Award in Basic Science. Spine 1982;7:184-91.

17. Adams MA, Hutton WC. Gradual disc prolapse. Spine 1985;10:524-31.

18. Adams MA, Freeman BJ, Morrison HP, Nelson IW, Dolan P. Mechanical initiation of intervertebral disc degeneration. Spine 2000;25:1625-36.

19. Holm S, Holm AK, Ekstrom L, Karladani A, Hansson T. Experimental disc degeneration due to endplate injury. J Spinal Disord Tech 2004;17:64-71. 
20. Zhao F, Pollintine P, Hole BD, Dolan P, Adams MA. Discogenic origins of spinal instability. Spine 2005;30:2621-30.

21. Pollintine P, Dolan P, Tobias JH, Adams MA. Intervertebral disc degeneration can lead to "stress-shielding" of the anterior vertebral body: a cause of osteoporotic vertebral fracture? Spine 2004;29:774-82.

22. Luo J, Skrzypiec DM, Pollintine P, Adams MA, Annesley-Williams DJ, Dolan P. Mechanical efficacy of vertebroplasty: Influence of cement type, BMD, fracture severity, and disc degeneration. Bone 2007;40:1110-9.

23. Pollintine P, van Tunen MS, Luo J, Brown MD, Dolan P, Adams MA. Timedependent compressive deformation of the ageing spine: relevance to spinal stenosis. Spine (Phila Pa 1976) 2010;35:386-94.

24. McMillan DW, Garbutt G, Adams MA. Effect of sustained loading on the water content of intervertebral discs: implications for disc metabolism. Ann Rheum Dis $1996 ; 55: 880-7$.

25. Adams MA, McNally DS, Dolan P. 'Stress' distributions inside intervertebral discs. The effects of age and degeneration. J Bone Joint Surg Br 1996;78:965-72.

26. McMillan DW, McNally DS, Garbutt G, Adams MA. Stress distributions inside intervertebral discs: the validity of experimental "stress profilometry'. Proc Inst Mech Eng [H] 1996;210:81-7.

27. McNally DS, Adams MA, Goodship AE. Development and validation of a new transducer for intradiscal pressure measurement. J Biomed Eng 1992;14:495-8.

28. Chu JY, Skrzypiec D, Pollintine P, Adams MA. Can compressive stress be measured experimentally within the annulus fibrosus of degenerated intervertebral discs? Proc Inst Mech Eng [H] 2008;222:161-70. 
29. Pollintine P, Przybyla AS, Dolan P, Adams MA. Neural arch load-bearing in old and degenerated spines. J Biomech 2004;37:197-204.

30. Dolan P, Earley M, Adams MA. Bending and compressive stresses acting on the lumbar spine during lifting activities. J Biomech 1994;27:1237-48.

31. Jiang G, Luo J, Pollintine P, Dolan P, Adams MA, Eastell R. Vertebral fractures in the elderly may not always be "osteoporotic". Bone 2010;47:111-6.

32. Green TP, Allvey JC, Adams MA. Spondylolysis. Bending of the inferior articular processes of lumbar vertebrae during simulated spinal movements. Spine 1994;19:2683-91. 33. Adams MA, Dolan P, Hutton WC. The stages of disc degeneration as revealed by discograms. J Bone Joint Surg [Br] 1986;68:36-41.

34. Zhao FD, Pollintine P, Hole BD, Adams MA, Dolan P. Vertebral fractures usually affect the cranial endplate because it is thinner and supported by less-dense trabecular bone. Bone 2009;44:372-9.

35. Adams MA. Mechanical testing of the spine. An appraisal of methodology, results, and conclusions. Spine 1995;20:2151-6.

36. Nachemson AL. Disc pressure measurements. Spine 1981;6:93-7.

37. Wilke HJ, Neef P, Caimi M, Hoogland T, Claes LE. New in vivo measurements of pressures in the intervertebral disc in daily life. Spine 1999;24:755-62.

38. McNally DS, Shackleford IM, Goodship AE, Mulholland RC. In vivo stress measurement can predict pain on discography. Spine 1996;21:2580-7.

39. Sato K, Kikuchi S, Yonezawa T. In vivo intradiscal pressure measurement in healthy individuals and in patients with ongoing back problems. Spine 1999;24:2468-74.

40. Brinckmann P, Biggemann M, Hilweg D. Prediction of the compressive strength of human lumbar vertebrae. Spine 1989;14:606-10. 
41. Hansson T, Roos B. The amount of bone mineral and Schmorl's nodes in lumbar vertebrae. Spine 1983;8:266-71.

42. Rolander SD, Blair WE. Deformation and fracture of the lumbar vertebral end plate. Orthop Clin North Am 1975;6:75-81.

43. Brinckmann P, Horst M. The influence of vertebral body fracture, intradiscal injection, and partial discectomy on the radial bulge and height of human lumbar discs. Spine 1985;10:138-45.

44. Tzermiadianos MN, Renner SM, Phillips FM, et al. Altered disc pressure profile after an osteoporotic vertebral fracture is a risk factor for adjacent vertebral body fracture. Eur Spine J 2008;17:1522-30.

45. Adams MA, McNally DS, Wagstaff J, Goodship AE. Abnormal stress concentrations in lumbar intervertebral discs following damage to the vertebral body: a cause of disc failure. Eur Spine J 1993;1:214-21.

46. Przybyla A, Pollintine P, Bedzinski R, Adams MA. Outer annulus tears have less effect than endplate fracture on stress distributions inside intervertebral discs: Relevance to disc degeneration. Clin Biomech 2006;21:1013-9.

47. Crock HV. Internal disc disruption. A challenge to disc prolapse fifty years on. Spine $1986 ; 11: 650-3$

48. Gunzburg R, Parkinson R, Moore R, et al. A cadaveric study comparing discography, magnetic resonance imaging, histology, and mechanical behavior of the human lumbar disc. Spine 1992;17:417-26.

49. Ranu HS. Multipoint determination of pressure-volume curves in human intervertebral discs. Ann Rheum Dis 1993;52:142-6.

50. Niemelainen R, Battie MC, Gill K, Videman T. The prevalence and characteristics of thoracic magnetic resonance imaging findings in men. Spine 2008;33:2552-9. 
51. Koeller W, Meier W, Hartmann F. Biomechanical properties of human intervertebral discs subjected to axial dynamic compression. A comparison of lumbar and thoracic discs. Spine 1984;9:725-33.

52. Panjabi MM, Goel V, Oxland T, et al. Human lumbar vertebrae. Quantitative threedimensional anatomy. Spine 1992;17:299-306.

53. Wagner DR, Reiser KM, Lotz JC. Glycation increases human annulus fibrosus stiffness in both experimental measurements and theoretical predictions. J Biomech 2006;39:1021-9.

54. Ishihara H, McNally DS, Urban JP, Hall AC. Effects of hydrostatic pressure on matrix synthesis in different regions of the intervertebral disk. J Appl Physiol 1996;80:83946.

55. Handa T, Ishihara H, Ohshima H, Osada R, Tsuji H, Obata K. Effects of hydrostatic pressure on matrix synthesis and matrix metalloproteinase production in the human lumbar intervertebral disc. Spine 1997;22:1085-91.

56. Walter BA, Korecki CL, Purmessur D, Roughley PJ, Michalek AJ, Iatridis JC. Complex loading affects intervertebral disc mechanics and biology. Osteoarthritis Cartilage 2011;19:1011-8.

57. Omlor GW, Nerlich AG, Wilke HJ, et al. A new porcine in vivo animal model of disc degeneration: response of anulus fibrosus cells, chondrocyte-like nucleus pulposus cells, and notochordal nucleus pulposus cells to partial nucleotomy. Spine 2009;34:2730-9.

58. Shirazi-Adl A. Finite-element simulation of changes in the fluid content of human lumbar discs. Mechanical and clinical implications. Spine 1992;17:206-12.

59. Kerttula LI, Serlo WS, Tervonen OA, Paakko EL, Vanharanta HV. Post-traumatic findings of the spine after earlier vertebral fracture in young patients: clinical and MRI study. Spine 2000;25:1104-8. 
60. Videman T, Battie MC, Gill K, Manninen H, Gibbons LE, Fisher LD. Magnetic resonance imaging findings and their relationships in the thoracic and lumbar spine. Insights into the etiopathogenesis of spinal degeneration. Spine 1995;20:928-35.

61. Niemelainen R, Battie MC, Videman T. Risk indicators for severe upper or mid back pain in men. Spine 2011;36:E326-33.

62. Williams FM, Manek NJ, Sambrook PN, Spector TD, Macgregor AJ. Schmorl's nodes: common, highly heritable, and related to lumbar disc disease. Arthritis Rheum 2007;57:855-60.

63. Luoma K, Vehmas T, Gronblad M, Kerttula L, Kaapa E. MRI follow-up of subchondral signal abnormalities in a selected group of chronic low back pain patients. Eur Spine J 2008; 17:1300-8.

64. Kerttula L, Luoma K, Vehmas T, Gronblad M, Kaapa E. Modic type I change may predict rapid progressive, deforming disc degeneration: a prospective 1-year follow-up study. Eur Spine J 2012;21:1135-42.

65. Kokubun S, Sakurai M, Tanaka Y. Cartilaginous endplate in cervical disc herniation. Spine 1996;21:190-5.

66. Veres SP, Robertson PA, Broom ND. The morphology of acute disc herniation: a clinically relevant model defining the role of flexion. Spine 2009;34:2288-96.

67. Rajasekeran S, Bajaj N, Tubaki V, Shetty A. An in-vivo study on 'Anatomy of failure' and proposal for a structural classification of Lumbar Disc Herniation. International Society for the Study of the Lumbar Spine (ISSLS). Amsterdam; 2012. 
Table 1: Details of 174 cadaveric specimens tested. Values refer to the number of specimens in each sub-group.

\begin{tabular}{|c|c|c|c|c|c|c|c|c|c|}
\hline \multicolumn{10}{|c|}{ Number of specimens tested $($ total $=174)$} \\
\hline \multirow{2}{*}{$\begin{array}{l}\text { Spinal } \\
\text { Level }\end{array}$} & \multirow[t]{2}{*}{$\mathrm{n}$} & \multicolumn{4}{|c|}{ Grade of disc degeneration } & \multicolumn{2}{|c|}{ Age (yrs) } & \multicolumn{2}{|c|}{ Gender } \\
\hline & & 1 & 2 & 3 & 4 & $<=60$ & $>60$ & Male & Female \\
\hline $\mathrm{T} 7-8$ & 6 & & 4 & 2 & & 2 & 4 & 2 & 4 \\
\hline T8-9 & 4 & & & 4 & & 1 & 3 & 2 & 2 \\
\hline T9-10 & 9 & & 5 & 3 & 1 & 3 & 6 & 3 & 6 \\
\hline T10-11 & 12 & & 5 & 7 & & 3 & 9 & 6 & 6 \\
\hline T11-12 & 17 & & 8 & 5 & 4 & 1 & 16 & 10 & 7 \\
\hline T12-L1 & 21 & & 11 & 9 & 1 & 4 & 17 & 12 & 9 \\
\hline L1-2 & 27 & & 11 & 13 & 3 & 4 & 23 & 12 & 15 \\
\hline L2-3 & 33 & 2 & 15 & 14 & 2 & 13 & 20 & 20 & 13 \\
\hline L3-4 & 23 & & 7 & 10 & 6 & 5 & 18 & 13 & 10 \\
\hline L4-5 & 20 & 4 & 8 & 7 & 1 & 12 & 8 & 13 & 7 \\
\hline L5-S1 & 2 & & 1 & 1 & & 2 & & 2 & \\
\hline Sub-totals & 174 & 6 & 75 & 75 & 18 & 50 & 124 & 95 & 79 \\
\hline
\end{tabular}


Table 2: Summary of results for various specimen groups. Values indicate the mean. $\mathrm{n}=$ number of specimens in each group. DD = grade of disc degeneration. The fall in intradiscal pressure (IDP) following endplate damage is given in absolute units (MPa), and also as a $\%$ of the Initial IDP before damage. "PA stress rise" = absolute increase in peak compressive stress (relative to IDP) measured in the posterior annulus, caused by endplate damage.

\begin{tabular}{|c|c|c|c|c|c|c|c|}
\hline 1 & 2 & 3 & 4 & 5 & 6 & 7 & 8 \\
\hline $\begin{array}{c}\text { Specimen } \\
\text { groups }\end{array}$ & $\mathrm{n}$ & Age (yrs) & $\begin{array}{c}\text { Initial IDP } \\
\text { (MPa) }\end{array}$ & $\begin{array}{c}\text { Damage } \\
(\mathrm{mm})\end{array}$ & $\begin{array}{c}\% \text { Fall in } \\
\text { IDP }\end{array}$ & $\begin{array}{c}\text { Fall in } \\
\text { IDP (MPa) }\end{array}$ & $\begin{array}{l}\text { PA stress } \\
\text { rise }(\mathrm{MPa})\end{array}$ \\
\hline All & 174 & 71 & 0.88 & 1.88 & 62 & 0.54 & 0.74 \\
\hline Male & 95 & 70 & 0.79 & 1.73 & 57 & 0.42 & 0.64 \\
\hline Female & 79 & 72 & 0.99 & 2.06 & 68 & 0.69 & 0.85 \\
\hline Age $<=60$ & 50 & 48 & 1.09 & 1.48 & 46 & 0.54 & 0.73 \\
\hline Age $>60$ & 124 & 80 & 0.79 & 2.05 & 69 & 0.54 & 0.74 \\
\hline DD - 1 & 6 & 24 & 0.98 & 0.81 & 5 & 0.05 & 0.03 \\
\hline DD - 2 & 75 & 65 & 1.00 & 1.79 & 56 & 0.57 & 0.79 \\
\hline DD - 3 & 75 & 77 & 0.86 & 1.98 & 68 & 0.60 & 0.71 \\
\hline DD - 4 & 18 & 84 & 0.47 & 2.21 & 80 & 0.34 & 0.86 \\
\hline T7-8 & 6 & 72 & 1.56 & 2.27 & 87 & 1.28 & 1.82 \\
\hline T8-9 & 4 & 74 & 1.27 & 2.16 & 93 & 1.19 & 1.09 \\
\hline T9-10 & 9 & 68 & 1.23 & 2.71 & 85 & 1.01 & 1.56 \\
\hline T10-11 & 12 & 74 & 0.87 & 2.44 & 89 & 0.79 & 0.49 \\
\hline T11-12 & 17 & 80 & 0.89 & 2.38 & 77 & 0.66 & 0.95 \\
\hline T12-L1 & 21 & 74 & 1.00 & 1.94 & 63 & 0.60 & 0.79 \\
\hline L1-2 & 27 & 77 & 0.85 & 1.89 & 71 & 0.59 & 0.85 \\
\hline L2-3 & 33 & 68 & 0.83 & 1.58 & 49 & 0.37 & 0.60 \\
\hline L3-4 & 23 & 71 & 0.64 & 1.92 & 48 & 0.29 & 0.43 \\
\hline L4-5 & 20 & 56 & 0.74 & 1.09 & 38 & 0.24 & 0.35 \\
\hline L5-S1 & 2 & 47 & 0.73 & 0.46 & 5 & 0.02 & 0.25 \\
\hline
\end{tabular}


Table 3 Summary of univariate linear regression results. A negative sign indicates an inverse relationship. Gender was coded 0 (female) and 1 (male), and spinal levels from T7-8 to L5-S1 were coded from 1 to 11 . Dependent (Y) variables represent changes following endplate damage.

\begin{tabular}{|c|c|c|c|c|c|c|}
\hline $\begin{array}{l}\text { Row } \\
\text { no. }\end{array}$ & $\begin{array}{l}\text { Dependent } \\
\text { (Y) variable }\end{array}$ & $\begin{array}{l}\text { Independent } \\
(\mathrm{X}) \text { variable }\end{array}$ & \multicolumn{2}{|c|}{$\begin{array}{l}\text { All discs } \\
(\mathrm{n}=174)\end{array}$} & \multicolumn{2}{|c|}{$\begin{array}{l}\text { Non-degenerated } \\
\operatorname{discs}(\mathrm{n}=81)\end{array}$} \\
\hline & & & Rsq & $\mathrm{P}$ & Rsq & $\mathrm{P}$ \\
\hline 1 & Damage (mm) & age & 17 & $<0.001$ & 14 & 0.001 \\
\hline 2 & & gender & -4 & 0.011 & -15 & $<0.001$ \\
\hline 3 & & spinal level & -20 & $<0.001$ & -34 & $<0.001$ \\
\hline 4 & & initial IDP & 0 & NS & 8 & 0.009 \\
\hline 5 & $\%$ Fall in IDP & age & 19 & $<0.001$ & 19 & $<0.001$ \\
\hline 6 & & gender & -3 & 0.031 & -9 & 0.006 \\
\hline 7 & & spinal level & -22 & $<0.001$ & -32 & $<0.001$ \\
\hline 8 & & initial IDP & 0 & NS & 1 & NS \\
\hline 9 & & damage & 37 & $<0.001$ & 51 & $<0.001$ \\
\hline 10 & Fall in IDP (MPa) & age & 2 & NS & 1 & NS \\
\hline 11 & & gender & -9 & $<0.001$ & -12 & 0.002 \\
\hline 12 & & spinal level & -33 & $<0.001$ & -35 & $<0.001$ \\
\hline 13 & & initial IDP & 49 & $<0.001$ & 44 & $<0.001$ \\
\hline 14 & & damage & 20 & $<0.001$ & 47 & $<0.001$ \\
\hline 15 & PA stress rise $(\mathrm{MPa})$ & age & 0 & NS & 0 & NS \\
\hline 16 & & gender & -1 & NS & -4 & NS \\
\hline 17 & & spinal level & -7 & $<0.001$ & -7 & 0.021 \\
\hline 18 & & initial IDP & 25 & $<0.001$ & 28 & $<0.001$ \\
\hline 19 & & damage & 4 & 0.007 & 10 & 0.003 \\
\hline 20 & & fall in IDP & 27 & $<0.001$ & 31 & $<0.001$ \\
\hline
\end{tabular}


Table 4 The best predictive model for disc decompression, obtained using multiple linear regression, explained $71 \%$ of the variance in 'Fall in IDP (MPa)'. Spinal level was coded from 1 (T7-8) to 11 (L5-S1), gender was coded 0 (female) and 1 (male), and disc degeneration graded from 1-4. Standardised (Std) coefficients indicate the relative importance of each influence. A '-ve' sign indicates an inverse relationship.

\begin{tabular}{|l|c|l|}
\hline \multicolumn{3}{|c|}{ All discs (n=174) $\mathbf{R}^{2}=\mathbf{7 1 \%}$} \\
\hline & Std coefficients & $\mathrm{P}$ \\
\hline Initial IDP (MPa) & 0.662 & $<0.001$ \\
\hline Damage (mm) & 0.244 & $<0.001$ \\
\hline Spinal level & $(-) 0.179$ & $<0.001$ \\
\hline Age (yrs) & 0.138 & 0.016 \\
\hline Gender & $(-) 0.066$ & NS \\
\hline Disc Degeneration & 0.058 & NS \\
\hline
\end{tabular}




\section{Figure Captions}

Figure 1 Cadaveric thoracolumbar motion segments were secured in cups of dental plaster, and compressed by means of two rollers, which maintained a neutral posture without inhibiting any settling movements in the horizontal plane. Black circles represent reflective markers that were attached to the lateral vertebral body cortex in some specimens: these enabled deformations to be measured optically, independent of deformations of other tissues and apparatus. The distribution of compressive stress was measured within the intervertebral disc by pulling a miniature pressure transducer along its mid-sagittal diameter.

Figure 2 Disc decompression (Fall in IDP) following endplate damage decreased regularly from T7-8 down to L5-S1, regardless of whether the disc was degenerated or not. 81 of the 174 specimens were non-degenerated (disc grade 1 or 2). Error bars indicate the standard error of the mean (SEM).

Figure 3 Disc decompression following vertebral endplate damage increased with age, but only in male specimens. In contrast, most female specimens aged over 40 yrs were substantially decompressed. Error bars indicate the SEM.

Figure 4 Average thickness of the vertebral body endplate was minimal at T11, and increased linearly from $\mathrm{T} 11$ to $\mathrm{L} 5\left(\mathrm{R}^{2}=21 \%, \mathrm{P}<0.001\right)$. Data refer to 80 undamaged vertebrae. 


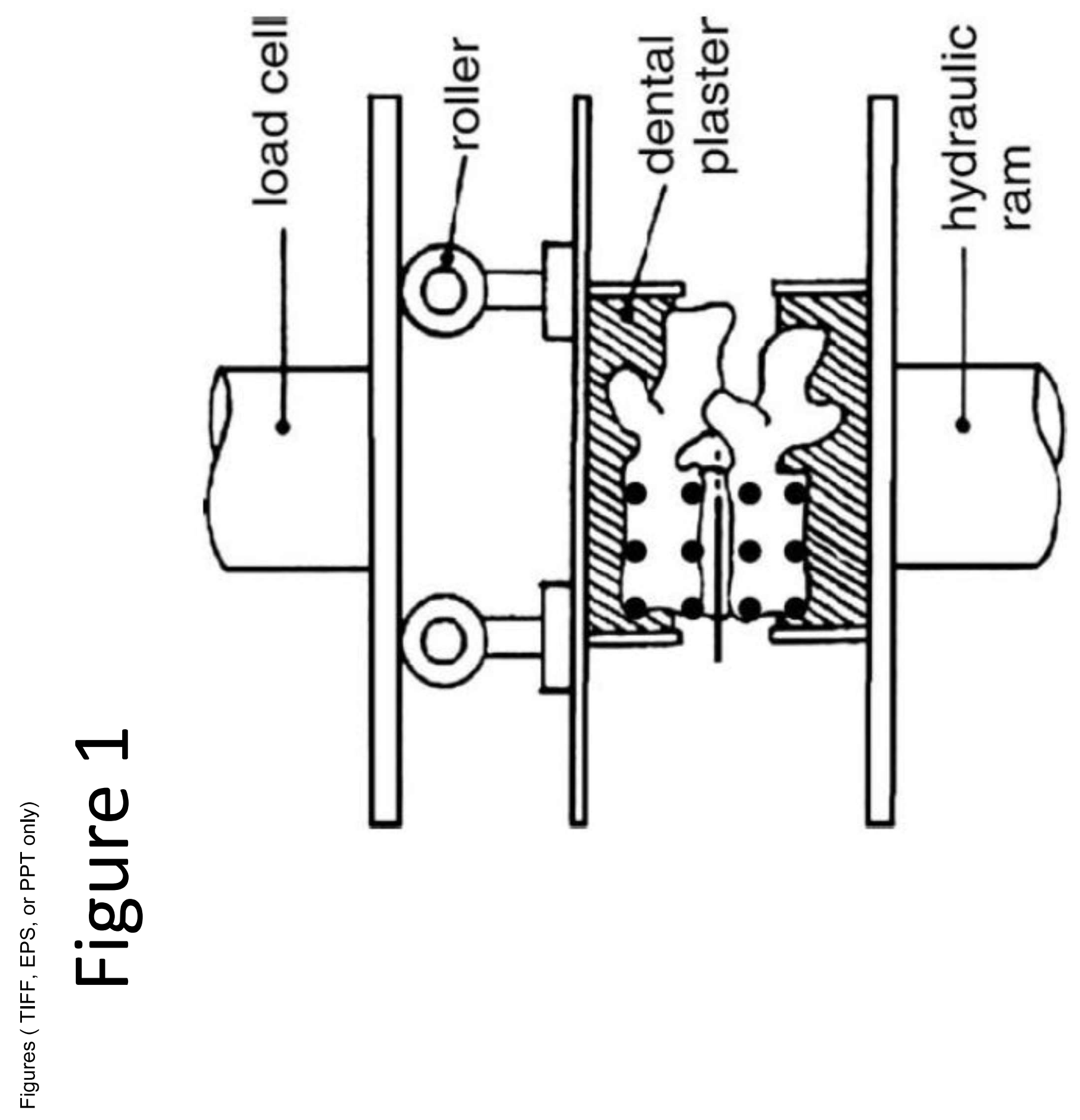




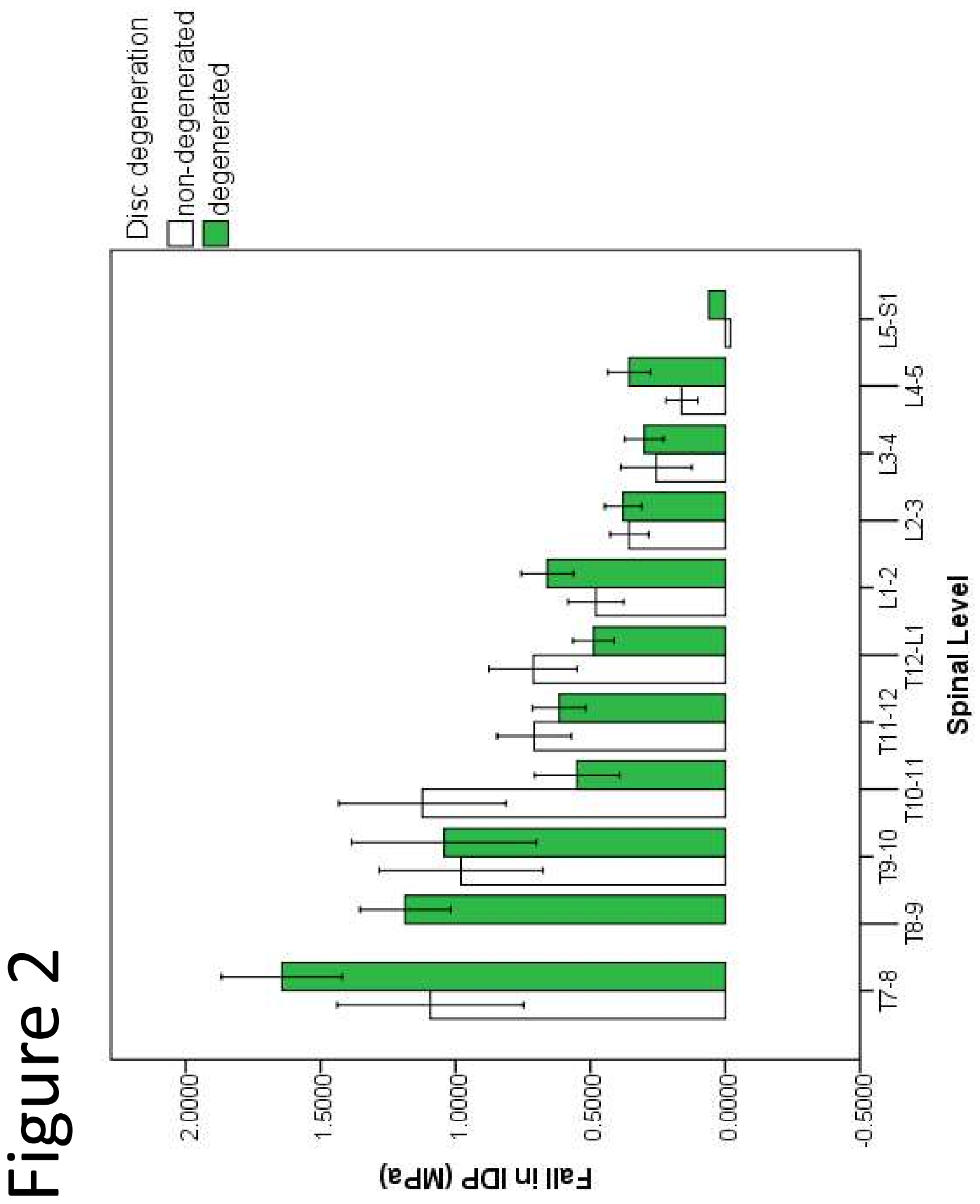




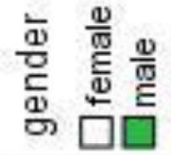

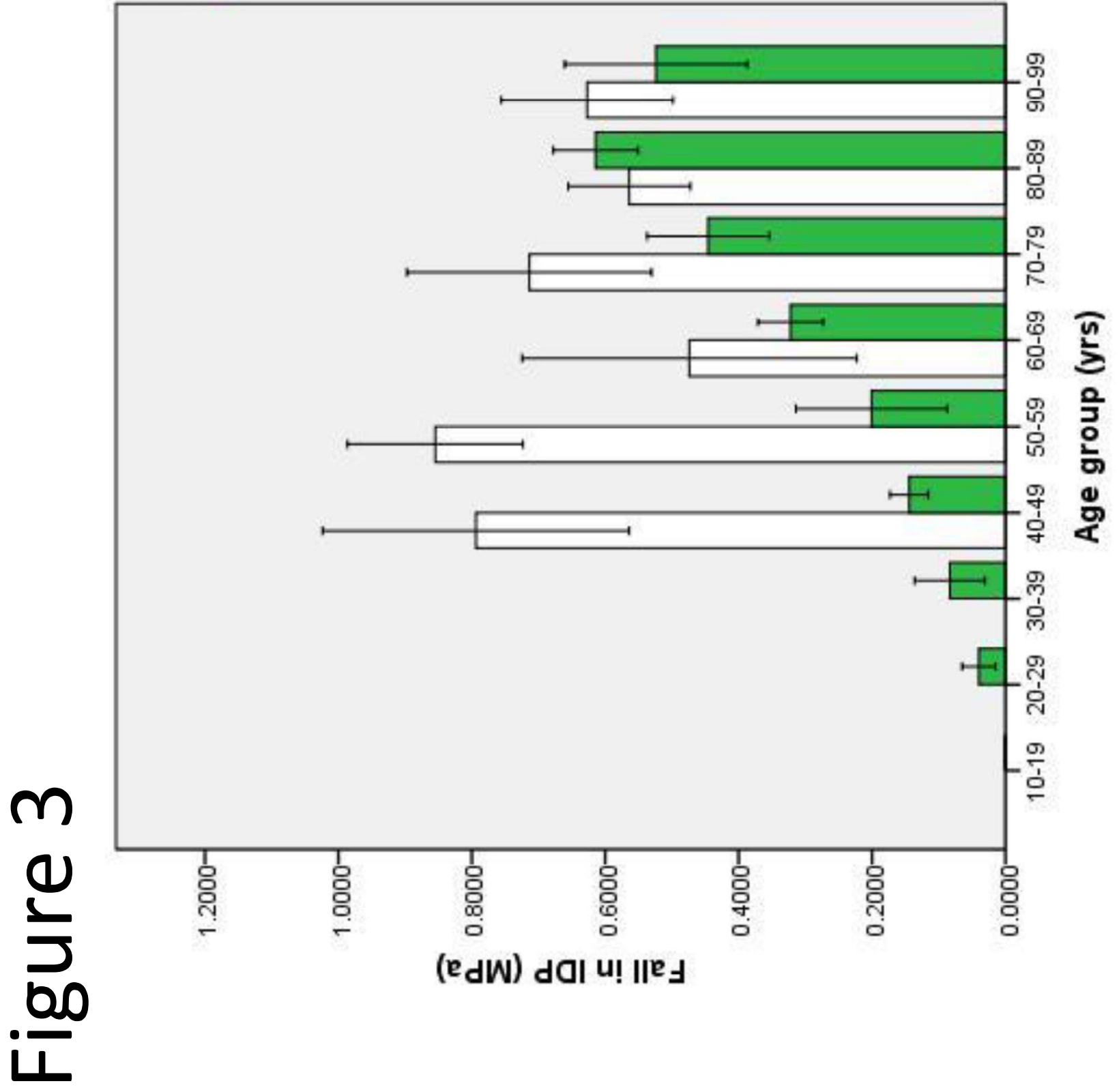




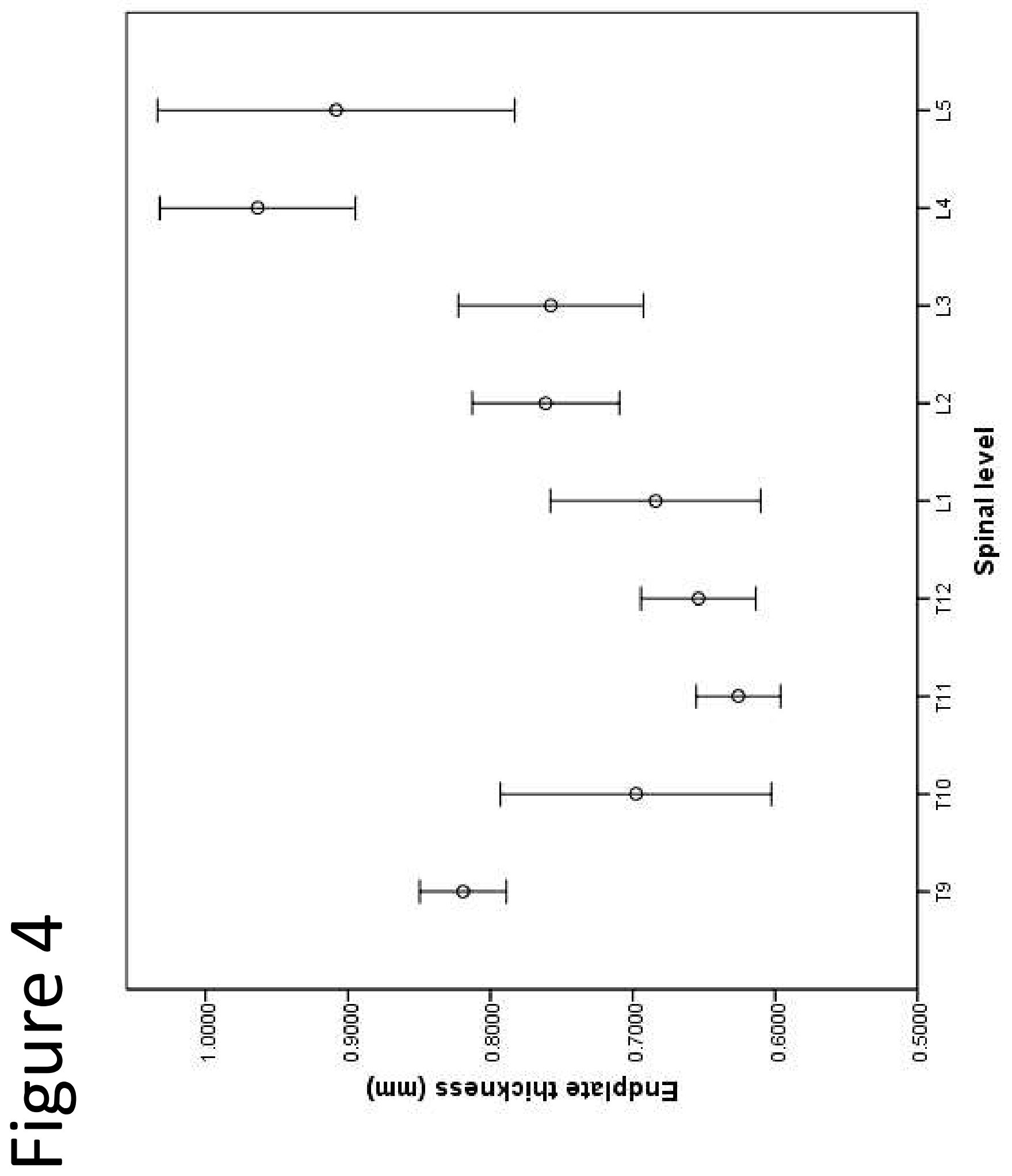

